Original Research Paper

\title{
Marking of Meat Productivity Features in Pairs of $b G H$, bGHR and bIGF-1 Polymorphic Genes in Aberdeen-Angus Cattle
}

\author{
${ }^{1}$ Laura Zhanedilovna Dushayeva, ${ }^{1}$ Askar Myrzahmetovich Nametov, ${ }^{1}$ Indira Saltanovna Beishova, \\ ${ }^{2}$ Alena Valentinovna Belaya, ${ }^{3 *}$ Tatyana Vladimirovna Ulyanova, ${ }^{1}$ Alexandr Mikhailovich Kovalchuk, \\ ${ }^{4}$ Khamit Kharisovich Tagirov and ${ }^{5}$ Yusupzhan Artykovich Yuldashbayev \\ ${ }^{I}$ Zhangir Khan West Kazakhstan Agrarian Technical University, Uralsk, Republic of Kazakhstan \\ ${ }^{2}$ Belarusian State Pedagogical University Named After Maxim Tank, Minsk, Republic of Belarus \\ ${ }^{3}$ A. Baitursynov Kostanay Regional University, \\ Ministry of Education and Science of the Republic of Kazakhstan, Kostanay, Republic of Kazakhstan \\ ${ }^{4}$ Bashkir State Agrarian University, Ufa, Russian Federation \\ ${ }^{5}$ Russian State Agrarian University-Moscow Timiryazev Agricultural Academy, Moscow, Russian Federation
}

\section{Article history}

Received: 11-03-2021

Revised: 06-04-2021

Accepted: 04-05-2021

Corresponding Author: Tatyana Vladimirovna Ulyanova

A. Baitursynov Kostanay Regional University, Ministry of Education and Science of the Republic of Kazakhstan, Kostanay, Republic of Kazakhstan Email: only.you1993@mail.ru

\begin{abstract}
The purpose of the study is to identify paired combinations associated with meat productivity in Aberdeen-Angus cattle for the genes of the somatotropin cascade (growth hormone $b G H$, growth hormone receptor $b G H R$, insulin-like growth factor-1 $b I G F-1)$. The determination of animal genotypes was carried out by PCR-RFLP. Results of statistical processing was carried out using the software capabilities of "Microsoft Excel 2010" and "Statistica 6.0". Paired combinations study of $b G H, b G H R$ and bIGF-1 somatotropin cascade revealed marking diplotype polymorphic genes associated with signs of meat productivity and allowing for a comprehensive assessment of the Aberdeen-Angus cattle genetic potential in the postnatal development early stages. Thus, the animals' live weight with the $b G H$ AluI $^{\mathrm{VV}}-b I G F-1-\mathrm{SnaBI}^{\mathrm{BB}}$ diplotype at the age of 24 months exceeds the Aberdeen-Angus breed live weight standard by $45 \mathrm{~kg} \mathrm{(12 \% )}$ and the total sample - by $12.52 \mathrm{~kg}(3 \%)$. The $b G H$-AluI ${ }^{\mathrm{LL}}-b I G F-1-\mathrm{SnaBI}^{\mathrm{AA}}$ diplotype score is $2.93 \%$ higher than the total sample. The mass index average value of animals with the $b G H-\mathrm{AluI}^{\mathrm{LV}}-b G H R-\mathrm{Sspl}^{\mathrm{FY}}$ diplotype at 18 months is $3.98 \%$ lower than the total sample. In animals with the $b G H R-\mathrm{SspI}^{\mathrm{FF}}-b I G F$ 1 -SnaBI ${ }^{\mathrm{BB}}$ diplotype at the age of 24 months, the churn index value is lower than the total sample by $3.74 \%$. Thus, the diplotypes $b G H$-AluI ${ }^{\mathrm{VV}}-b I G F-1$ $\mathrm{SnaBI}^{\mathrm{BB}}$ and $b G H$-AluI ${ }^{\mathrm{LL}}-b I G F-1-\mathrm{SnaBI}^{\mathrm{AA}}$ can be considered genetic markers of increased meat productivity and the diplotypes $b G H-\mathrm{AluI}^{\mathrm{LV}}-b G H R-\mathrm{SspI}^{\mathrm{FY}}$ and $b G H R-\mathrm{SspI}^{\mathrm{FF}}-b I G F-1-\mathrm{SnaBI}^{\mathrm{BB}}$-reduced meat productivity. The animals' selection with diplotypes that increase meat productivity will reduce the investment period and increase the agricultural production profitability. For breeding activities, it is recommended to maintain the animals' number with the diplotypes $b G H$-AluI ${ }^{\mathrm{VV}}-b I G F-1-\mathrm{SnaBI}^{\mathrm{BB}}$ and $b G H$-AluI ${ }^{\mathrm{LL}}-b I G F-1-\mathrm{SnaBI}^{\mathrm{AA}}$.
\end{abstract}

Keywords: Aberdeen-Angus Breed, Meat Productivity, PCR-RFLP

\section{Introduction}

The information uses specific polymorphic genes on the phenotypic effects that control the farm animals' quantitative indicators is one of the accurate, fast and relatively inexpensive tools for genetic productivity control (Zhang et al., 2020; Purfield et al., 2019).
Currently, the search for effective genetic markers is carried out among various candidate genes for different indicators in different breeds and new methods and approaches are being developed to increase its accuracy and efficiency (Beishova et al., 2018; Raza et al., 2019; Wu et al., 2019; Xiang et al., 2019; Gui et al., 2020; Liu et al., 2020; Wang et al., 2020). 
Many foreign scientists have studied the AberdeenAngus breed. Fedota et al. (2017a) when studying the Aberdeen-Angus breed, revealed that the allele $\mathrm{C}$ of the growth hormone gene polymorphism g. $2141 \mathrm{C}>\mathrm{G}$ has a positive correlation with live birth weight, overall appearance score, shorter calving interval and a negative correlation with average daily calf growth. The $t$ allele of the growth hormone gene polymorphism g. 914T > A has a positive correlation with muscle and udder size; live weight at all ages and average daily weight gain. Posivnikova (2017) found the positive effect of the LV genotype of the $b G H$ gene and the AA genotype of the bPit- 1 gene (live weight at the age of 7 months, average daily weight gain) on the growth and development of young Aberdeen Angus breeds and bulls with the BB genotype of the bPit-1 gene at the age of 12 months had a higher live weight. Lysenko et al. (2016) found that alleles from the bCapnl and bCasT genes that are desirable from the point of meat tenderness view positively correlate with an increase in the size of the Angus animals' chest (bCapnl) and musculature (bCasT). Barendse et al. (2007) studies on the Angus breed revealed that the G/G genotype of the $b R O R C$ gene encoding the retinoic acid receptor has a positive effect on marbling. Hohmann et al. (2020) studied the milk casein genes polymorphism in Angus breed females of the German population and determined the maternal casein genotypes influence on their calves' growth characteristics. It was found that calves from females with the K-CN BB and $\alpha$ s1-CN BB genotypes had higher indicators of average daily growth and live weight at weaning. Szewczuk (2016), in the silent SNP (rs41961336; C $\rightarrow$ T) study in exon 7 of the bIGF1R gene in Angus cattle, revealed that heifers with the $\mathrm{CC}$ genotype were heavier than individuals with the CT genotype, but individuals with the CT genotype had a significantly higher body weight at the first hotel.

Earlier, studies on the candidate genes that regulate the milk productivity signs in Holstein and black-and-white cattle of Belarusian selection (Belaya et al., 2012a) and studies on the meat productivity indicators in cattle of Auliekol and Kazakh white-headed breeds of Kazakhstan selection (Nametov et al., 2018), we noted that the observed in some cases insufficiently high efficiency of breeding measures using marker-related selection is due to the fact that the phenotypic effects of preferred and undesirable genotypes, in essence, they are the marginal values of the reaction rate for this indicator and proposed a method for assessing the phenotypic effects of candidate genes relative to the total sample.

Also, in our previous study on the phenotypic effects of somatotropin cascade genes, we found that the phenotypic effect of genetic markers is enhanced if the animal genotype contains genetic markers that potentiate each other's effect. Therefore, we used the somatotropin cascade genes, the protein products which are the key links in a single humoral chain involved in growth and development of mammals ( $b G H, b G H R, b I G F-1)$
(Belaya et al., 2012b). In this case, the expression of one gene affects the expression of all the others and one polymorphism potentiates the action of the other.

This article presents the study results polymorphic genes combined phenotypic effects of the bGH, bGHR, bIGF-1 somatotropin cascade on such meat productivity, as physique and live weight indexes in commercial ages 18 and 24 months in pedigree bulls of breed Aberdeen-Angus of Kazakhstan selection.

\section{Materials and Methods}

All procedures performed in this study were in accordance with ethical standards. The research work was approved by the National research Council of the National center of state scientific and technical expertise of the Committee of science of Ministry of education and science on priority direction "Sustainable development of agriculture and safety of agricultural products" (minutes of meeting No. 1 of 12 January 2018).

The material served as samples of breeding steers tissue of birth 2015 year of Aberdeen-Angus breed of the Kazakhstan selection. Animals were taken from the farms of the same territorial affiliation with equal conditions for feeding and keeping (LLP "Sever-Agro-N", Farm "Seydahmetov" of Kostanay region). The sample size was 284 samples. Determination of genotype of animals was carried out by PCR-RFLP by (Table 1).

The restriction reaction of the obtained amplification products of the $b G H, b G H R$ and $b I G F-1$ genes was carried out using restriction endonucleases AluI, SspI and SnaBI, respectively. After incubation, the restriction fragments were separated in $2 \%$ agarose gel at $90 \mathrm{~V}$ for $120 \mathrm{~min}$. To visualize the electrophoresis results, a Quantum model 1100 computer system, Vilber Lourmat (USA) was used. The restriction fragments size was determined using the TrackIt тм molecular weight marker 50 bp DNA Ladder. For genotyping of individuals for each of the loci, the lengths of restriction fragments on electrophoregrams were compared. Analysis of the nucleotide sequence polymorphism of the $b G H$ gene in exon 5 is performed using gel electrophoresis according to (Skinkyte et al., 2005), Fig. 1.

Analysis of the nucleotide sequence polymorphism of the $b G H R$ gene in exon 8 was performed according to (Fontanesi et al., 2007) (Fig. 2).

The nucleotide sequence polymorphism of the insulin-like growth factor-1 gene $b I G F-1$ in the P1 region of the promoter region was identified according to (Hines et al., 1998) (Fig. 3).

The genotype of the animal for all analyzed genes is documented and entered into a common database. According to the genotyping results, the animals were divided into appropriate groups. The animals' percentage was calculated from the total sample (284 heads). Evaluation of the somatotropin cascade genes bGH-AluI, bGHR-SspI, и bIGF-1-SnaBI polymorphisms as meat productivity genetic 
markers in Aberdeen-Angus calves included: 1. Preferred and alternative genotypes determination by comparing productivity indicators in the corresponding animal groups; 2. Comparison of productivity indicators in animal groups with preferred and undesirable genotypes relative to the total sample and significance assessment of the observed differences. If statistically significant differences were found in animals with preferred and undesirable genotypes from the General sample, the difference in the average values of productivity indicators for genotypes was calculated as a percentage in comparison with the average values of productivity indicators for the General study sample; in the case of the live weight indicator, the difference was calculated in $\mathrm{kg}$ and as a percentage, additionally in comparison with the Aberdeen-Angus breed standard. The breed standard is the minimum requirements for assigning animals to class I. So, the live weight of the AberdeenAngus breed of class I at the age of 18 months is $330 \mathrm{~kg}$, at the age of 24 months-380 kg (MARK, 2008).

Table 1: PCR modes for the studied polymorphic loci of somatotropin cascade genes

\begin{tabular}{|c|c|c|c|}
\hline Poly-Morphism & Gene region & Terms of Amplification & Primer Sequence \\
\hline \multirow[t]{2}{*}{ bGH-AluI (Skinkytė et al., 2005) } & Exon 5 & $95^{\circ} \mathrm{C}-5 \mathrm{~min} ;\left(95^{\circ} \mathrm{C}-3^{\circ} \mathrm{sec} ; 64^{\circ} \mathrm{C}-3^{\circ} \mathrm{sec} ; 72^{\circ} \mathrm{C}-6^{\circ}\right.$ & AluI-F: 5'-ccgtgtctatgagaagc-3' \\
\hline & & sec) $\times 35^{\circ}$ cycles; $72^{\circ} \mathrm{C}-1^{\circ} \mathrm{min}$ & AluI-R: $5^{\prime \prime}$-gttcttgagcagcgcgt-3' \\
\hline bGHR-SspI (Fontanesi et al., 2007) & Exon 8 & $95^{\circ} \mathrm{C}-5 \mathrm{~min} ;\left(95^{\circ} \mathrm{C}-3^{\circ} \mathrm{sec} ; 6^{\circ} \mathrm{C}-3^{\circ} \mathrm{sec} ; 72^{\circ} \mathrm{C}\right.$ & \\
\hline \multirow[t]{2}{*}{ bIGF-1-SnaBI (Siadkowska et al., 2006) } & $\mathrm{P} 1$ region of the & $95^{\circ} \mathrm{C}-5 \mathrm{~min} ;\left(95^{\circ} \mathrm{C}-30 \mathrm{sec} ; 64^{\circ} \mathrm{C}-30\right.$ & SnaBI-F: 5'-attcaaagctgcctgcccc-3' \\
\hline & promoter region & $\left.\mathrm{sec} ; 72^{\circ} \mathrm{C}-30 \mathrm{sec}\right) \times 35 \mathrm{t} . ; 72^{\circ} \mathrm{C}-10 \mathrm{~min}$. & SnaBI-R: 5'-acacgtatgaaaggaact-3' \\
\hline
\end{tabular}

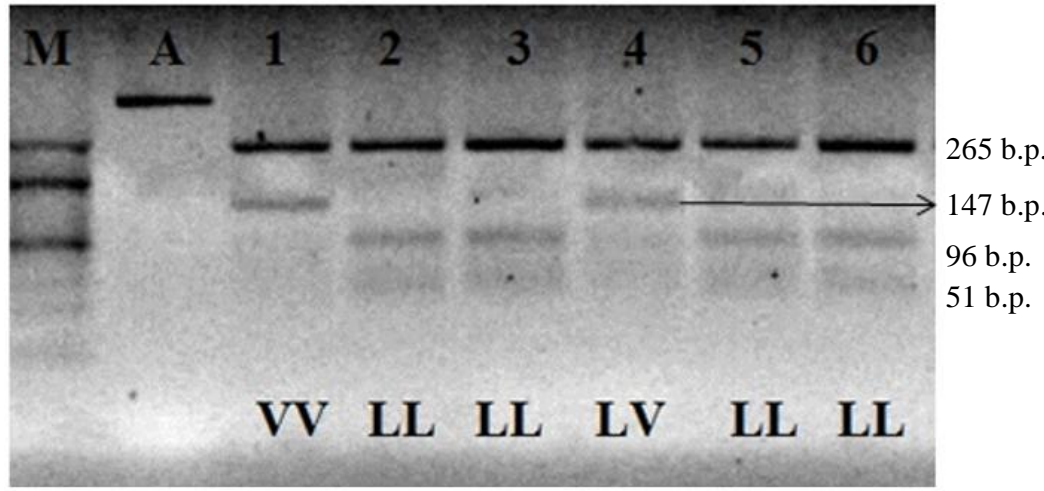

Fig. 1: DNA typing electrophoregram $b G H$-AluI polymorphism. Tracks 2, 3, 5, 6 - restriction fragments $265,96,51$ bp, corresponding to $b G H$-AluI ${ }^{\mathrm{LL}}$ genotype; track 4 - restriction fragments $265,147,96$ и $51 \mathrm{bp}$, corresponding to $b G H$-AluI ${ }^{\mathrm{LV}}$ genotype; track 1 restriction fragments 265 and $147 \mathrm{bp}$, corresponding to $b G H$-AluI ${ }^{\mathrm{VV}}$ genotype. The restriction fragment of 16 bp is not visualized. The position of specific bands on the gel is indicated by arrows. Electrophoresis was performed in $2 \%$ agarose gel (SeaKem LE Agarose, Lonza, USA)

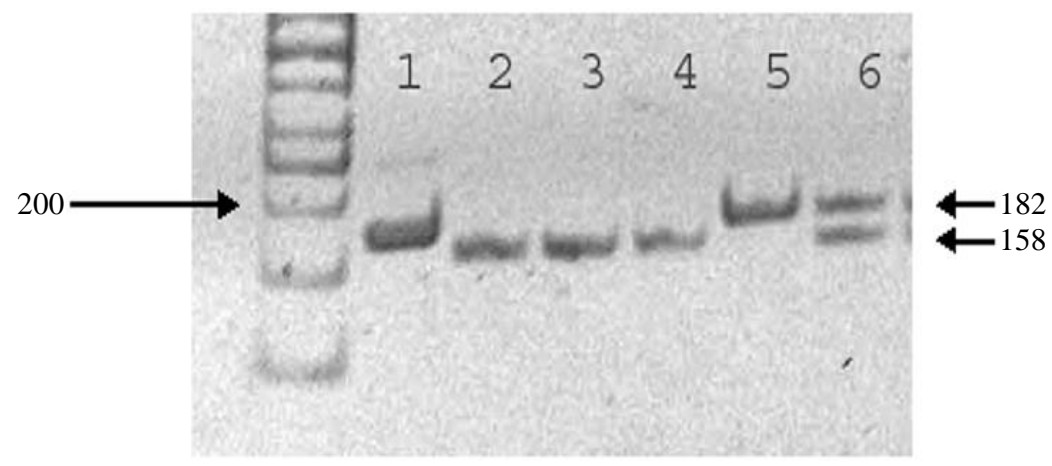

Fig. 2: DNA typing electrophoregram $b G H R$-SspI polymorphism (Belaya et al., 2012a). Track 1 - PCR- product 182 bp gene fragment of the $b G H R$-SspI gene; tracks 2, 3, 4-restriction fragment 158 bp corresponding to the $b G H R$-SspI ${ }^{\mathrm{FF}}$ genotype; track 5restriction fragment $182 \mathrm{bp}$ corresponding to the $b G H R-\mathrm{SspI}^{\mathrm{YY}}$ genotype; track 6-restriction fragments 182 and $158 \mathrm{bp}$ corresponding to the $b G H R-\mathrm{SspI}^{\mathrm{FY}}$ genotype. The 24-point fragment is not visualized. The molecular mass marker $\mathrm{O}^{\prime}$ RangeRuler ${ }^{\mathrm{tm}} 50 \mathrm{bp}$ DNA Ladder, Fermentas, Lithuania was used. The position of specific bands on the gel is indicated by arrows. Electrophoresis was performed in $2 \%$ agarose gel (SeaKemLEAgarose, Lonza, USA) 


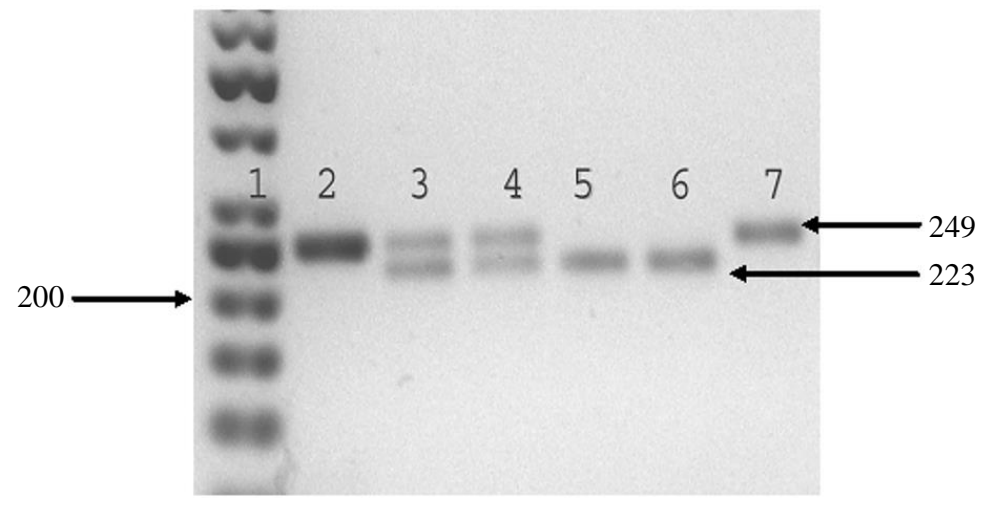

Fig. 3: Electrophoregram of DNA typing of the bIGF-1-SnaBI polymorphism (Belaya et al., 2012a). Track 1-molecular mass marker O'Range Ruler TM 50 bp DNA Ladder, Fermentas, Lithuania; track 2 - PCR-product of 249 bp of the bIGF-1-SnaBI gene fragment; tracks 3, 4-restriction fragments 249 and 223 bp corresponding to the $b I G F-1$-SnaBI ${ }^{A B}$ genotype; track 5, 6-restriction fragment $223 \mathrm{bp}$ corresponding to the bIGF-1-Spaviaa genotype; track 7-restriction fragment $249 \mathrm{bp}$, corresponding to the genotype $b I G F-1-\mathrm{SnaBI}^{B B}$. The $26 \mathrm{bp}$ fragment is not visualized. The position of specific bands on the gel is indicated by arrows. Electrophoresis was performed in $2 \%$ agarose gel (SeaKem LE Agarose, Lonza, USA)

Since the small sample size imposes additional limitations on the degree of obtained results reliability, the methods of nonparametric statistics were used for analysis, allowing to work with small samples in the absence of feature Gaussian distribution. The data are presented as median and interquartile range.

The statistical estimation differences between groups with three possible genotypes was performed by KruskelWallis ANOVA using rank analysis of variations for three or more independent groups. If the animal numbers in a group with a rare genotype was less than six, this group was excluded from statistical processing and comparison was performed using the Mann-Whitney U-test for two independent groups. The differences in all cases were considered statistically significant at a significance level of $\mathrm{P}<0.05$ (Rebrova, 2002).

For those polymorphisms in which differences between preferred and alternative genotypes were statistically significant, as well as for groups with paired combinations of genotypes, productivity was estimated relative to the total sample by constructing a $95 \%$ confidence interval for the median of the analyzed group and then comparing it with the total samples' median. This method allows you to evaluate the differences between the group that is part of the sample and the sample itself. The data is presented as the median of the lower and upper bounds of the $95 \%$ confidence interval. In the case that the boundaries of the CI do not overlap, it is concluded that the analyzed group was significantly different from the population. Data are analyzed, presented and discussed in the form of Me, [CI1; CI2] (25\%; 75\%) (Rebrova, 2002).

Sequence number of sample values that are Lower $(\mathrm{L})$ and Upper (U) boundaries were determined by the formulas 1 and 2 :

$$
\begin{aligned}
& L=n / 2-(Z 1-\alpha * \sqrt{ } n / 2) \\
& U=1+n / 2+(Z 1-\alpha * \sqrt{ } n / 2)
\end{aligned}
$$

where, the $Z$ - value of normal distribution for selected probabilities. For a confidence probability of $95 \%, \mathrm{Z}=$ 1.96 (Rebrova, 2002) $n$ is the sample size.

The results were processed using the software features "Microsoft Excel 2010" and "Statistica 6.0" (StatSoft, IP. 1994-2001). The Basic Statistical tables and Nonparametric Statistics modules are required (Rebrova, 2002).

\section{Results}

The average value $( \pm \sigma)$ of live weight for the study group was $359.79 \pm 0.72$ at the age of 18 months and $416.68 \pm 0.90$ at the age of 24 months. The average value of the downness index was $84.43 \pm 0.25$ and $84.38 \pm 0.21$ at the ages of 18 and 24 months, respectively, the massiveness index was $103.34 \pm 0.28$ and $107.09 \pm 0.32$, the elongation index was $119.29 \pm 0.26$ and $127.06 \pm 0.40$, the bony index was 15.07 \pm 0.06 and $15.69 \pm 0.06$ and the posterior index was $226.33 \pm 1.64$ and $212.59 \pm 1.57$, respectively, at the ages of 18 and 24 months.

The results groups with different genotypes of evaluating the heterogeneity for the $b G H$-AluI, $b G H R$-SspI and $b I G F$ SnaBI polymorphisms are presented in Table 2.

Productivity evaluation of these animal groups using the confidence interval method revealed a case where the 95\% confidence interval boundaries of the group fall outside the boundaries of the $95 \%$ confidence interval of the sample as a whole (Fig. 4). 
According to the results of DNA typing, animals with the corresponding paired combinations of genotypes were divided into corresponding groups (diplotypes). The meat productivity of each diplotype was analyzed in relation to the total sample according to the characteristics of live weight at the ages of 18 and 24 months, as well as by the physique, compactness and bone, index of format indices, narrow quarters and mass at the age of 18- and 24-months indices.

When analyzing the phenotypic effects of paired combinations of polymorphic genes of the somatotropin cascade on meat productivity indicators in AberdeenAngus calves, significant phenotypic effects were established for paired combinations No. $15 b G H-A l u I^{V^{V}}$ $b I G F-1-\mathrm{SnaBI}^{\mathrm{BB}}$ (index of live weight at 24 months), No. $11 b G H-\mathrm{AluI}^{\mathrm{LV}}-b G H R-\mathrm{SspI}^{\mathrm{FY}}$ (mass index at 18 months), No. $25 b G H R-\mathrm{SspI}^{\mathrm{FF}}-b I G F-1-\mathrm{SnaBI}^{\mathrm{BB}}$ and No.1 $b G H$ AluI ${ }^{\mathrm{LL}}$-bIGF-1-SnaBI ${ }^{\mathrm{AA}}$ (Index of Compactness at 24 months) (Table 3).
The results of a significance graphical analysis of the difference between the group with diplotype No.15 $b \mathrm{GH}$ AluI ${ }^{\mathrm{VV}}-b I G F-1-\mathrm{SnaBI}^{\mathrm{BB}}$ from the total sample on the basis of live weight index at the age of 24 months (Fig. 5).

The graphical analysis results of the significance of the difference between the group with diplotypes No. 25 $b G H R-\mathrm{SspI}^{\mathrm{FF}}-b I G F-1-\mathrm{SnaBI}^{\mathrm{BB}}$ and No. $1 b G H-\mathrm{AluI}^{\mathrm{LL}}$ $b I G F-1-\mathrm{SnaBI}^{\mathrm{AA}}$ from the total sample by the down index at the age of 24 months (Fig. 6).

The graphical analysis results of the significance of the difference between the group with diplotype No. $11 \mathrm{bGH}$ AluI $^{\mathrm{LV}}-b G H R-\mathrm{SspI} \mathrm{F}^{\mathrm{FY}}$ from the General sample by the mass index at the age of 18 months (Fig. 7).

The relative frequencies of structure-forming genotypes are given in the same place for comparison (Fig. 8).

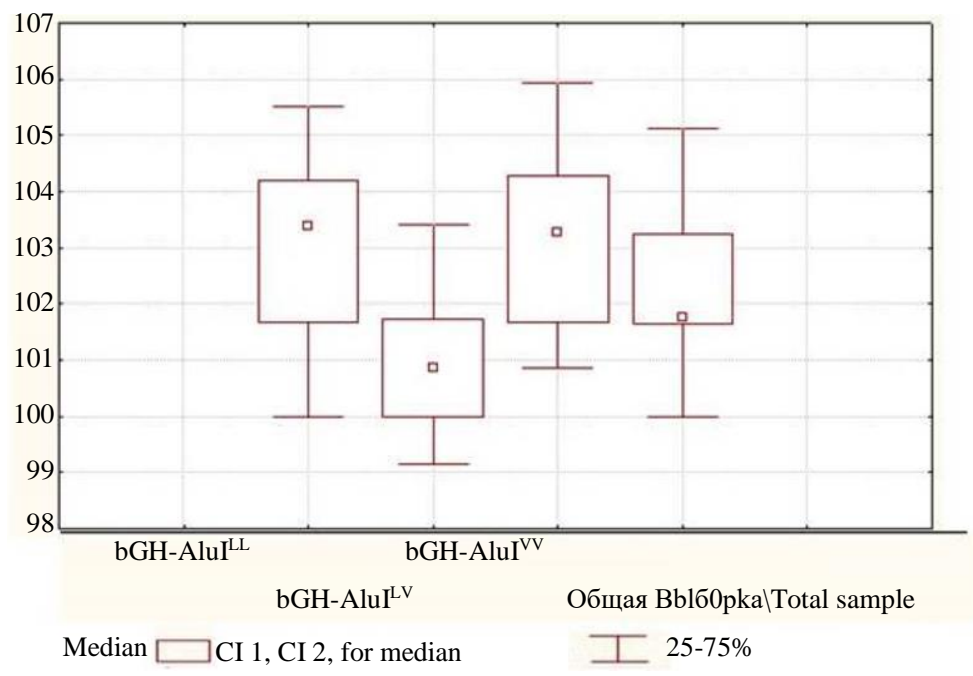

Fig. 4: Interval estimation of the mass index at the age of 24 months in Aberdeen-Angus calves with the genotypes $b G H$-AluI ${ }^{\mathrm{LL}}, b G H$ $\mathrm{AluI}^{\mathrm{LV}}$ and $b G H-\mathrm{AluI}{ }^{\mathrm{VV}}$ relative to the total sample

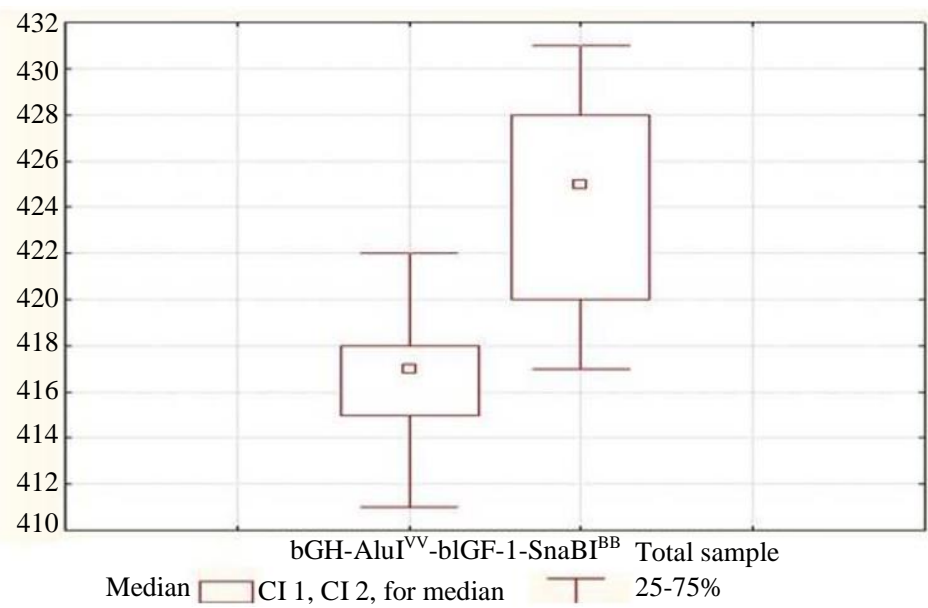

Fig. 5: Graphical assessment of the statistical significance of the phenotypic effect of diplotype No. $15 b G H-\mathrm{AluI}^{\mathrm{VV}}-b I G F-1-\mathrm{SnaBI}{ }^{\mathrm{BB}}$ on the live weight Aberdeen-Angus calves at the age of 24 months basis 


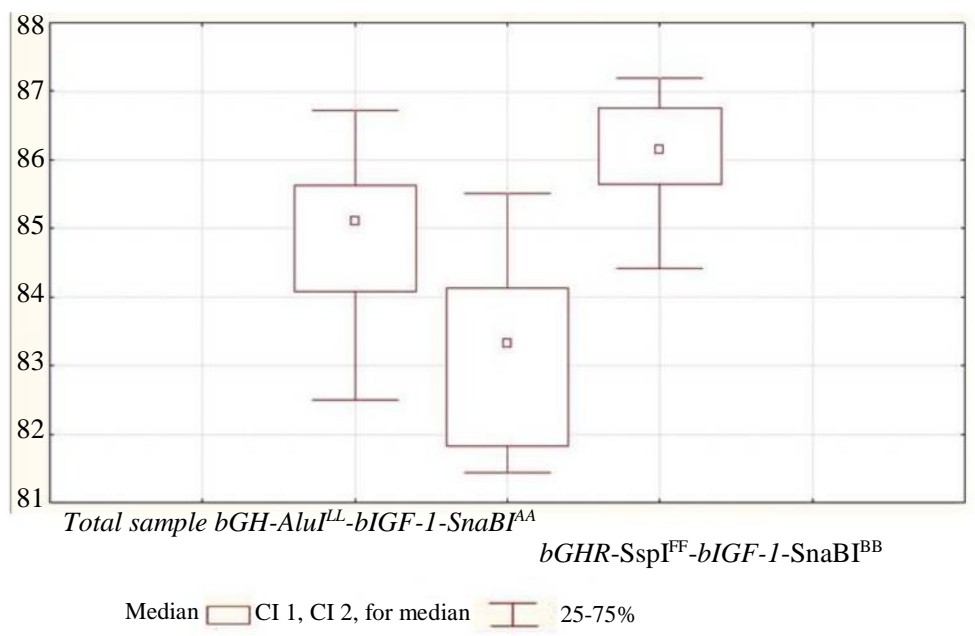

Fig. 6: Graphical assessment of the statistical significance of the phenotypic effects of diplotypes No. 25 bGHR-SspI ${ }^{\mathrm{FF}}$ - $b I G F-1-$ $\mathrm{SnaBI}^{\mathrm{BB}}$ and No. $1 b G H$-AluI ${ }^{\mathrm{LL}}-b I G F-1-\mathrm{SnaBI}^{\mathrm{AA}}$ on the Index of Compactness of Aberdeen-Angus calves aged 24 months

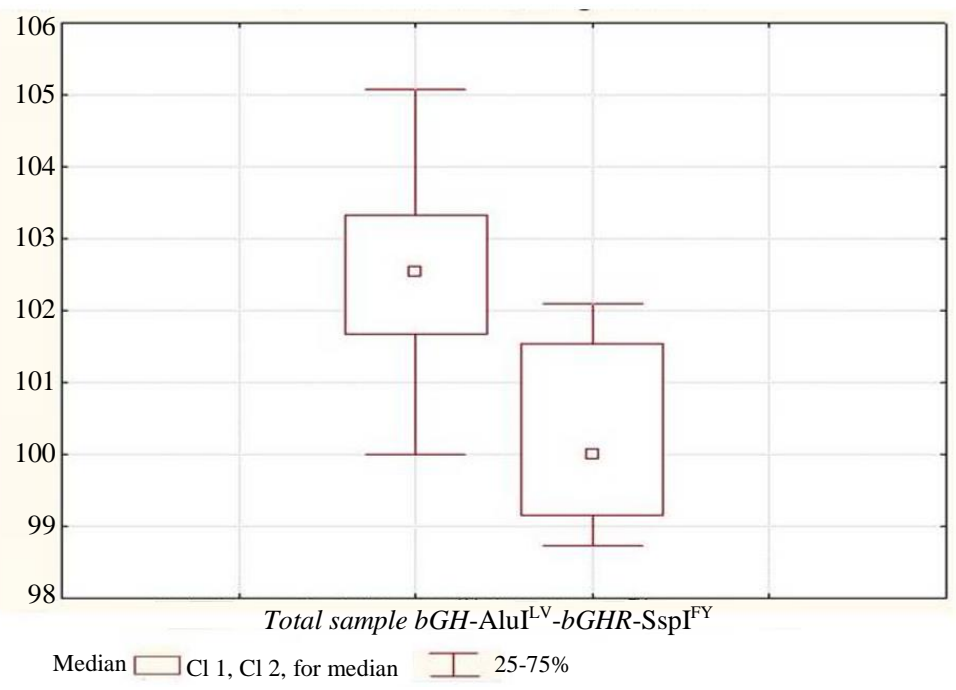

Fig. 7: Graphical assessment of the statistical significance of the phenotypic effect of diplotype No. $11 b G H-\mathrm{AluI}^{\mathrm{LV}}-b G H R-\mathrm{SspI} \mathrm{FY}^{\mathrm{FY}}$ on the mass index of Aberdeen-Angus calves aged 18 months

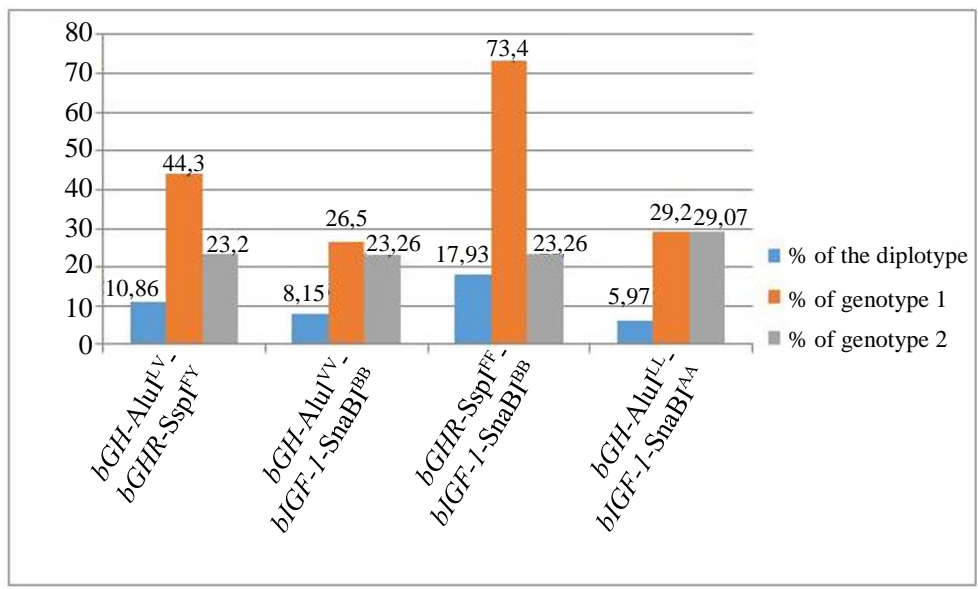

Fig. 8: Distribution of relative frequencies of marking diplotypes in Aberdeen-Angus cattle breed 
Table 2: P-statistic values when assessing the heterogeneity of groups with different genotypes according to Kruskal-Wallis for polymorphisms $b G H$-AluI, $b G H R$-SspI and $b I G F$-SnaBI in Aberdeen-Angus calves

\begin{tabular}{llll}
\hline Polymorphism & $b G H$-AluI & $b G H R$-SspI & $b I G F-$ SnaBI \\
\hline Comparable genotypes & LL, LV, VV & FF, FY, YY & AA, AB, BB \\
Live weight at the age of 18 months & 0.32 & 0.48 & 0.47 \\
Live weight at the age of 24 months & $0.02^{*}$ & 0.12 & 0.31 \\
Index of Compactness at the age of 18 months & 0.09 & 0.22 & 0.65 \\
Index of Compactness at the age of 24 months & 0.60 & 0.66 & 0.07 \\
Index of Bone at the age of 18 months & $0.05^{*}$ & 0.84 & 0.13 \\
Index of Bone at the age of 24 months & 0.56 & 0.97 & 0.10 \\
Index of Format at the age of 18 months & 0.22 & 0.40 & 0.25 \\
Index of Format at the age of 24 months & 0.53 & 0.27 & 0.47 \\
Index of narrow quarters at the age of 18 months & 0.11 & 0.40 & 0.11 \\
Index of narrow quarters at the age of 24 months & $0.01 *$ & 0.27 & 0.14 \\
Mass index at the age of 18 months & 0.74 & 0.69 & 0.89 \\
Mass index at the age of 24 months & & 0.51 \\
\hline
\end{tabular}

Note: *The samples are heterogeneous relative to each other at $\mathrm{P} *<0.05$ (according to Kruskal-Wallis)

Table 3: Characteristics of the growth and development dynamics of Aberdeen-Angus calves with marking paired genotype combinations (Me [CI 95\%], $(25 \% ; 75 \%)$ )

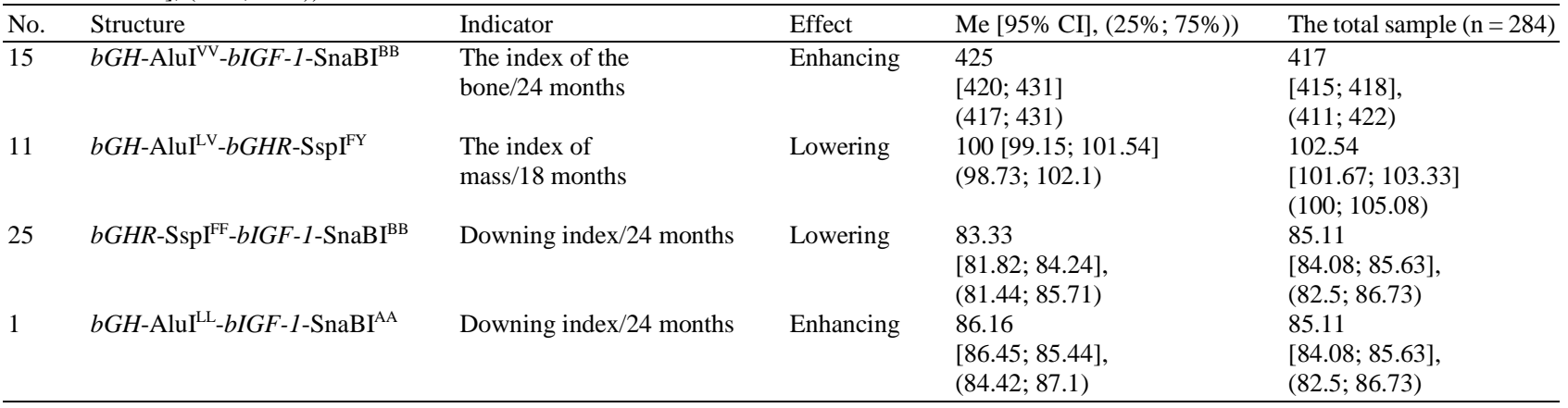

In Aberdeen-Angus calves aged 18 months, diplotype No.11 $b G H$-AluI ${ }^{\mathrm{LV}}-b G H R$-SspI ${ }^{\mathrm{FY}}$ was a marker of a reduced mass index. Its frequency in the population was quite high at $10.86 \%$, while the frequencies of the structureforming genotypes $b G H$-AluI ${ }^{\mathrm{LV}}$ and $b G H R-\mathrm{SspI}^{\mathrm{FY}}$ are 44.3 and $23.2 \%$, respectively. A decrease in the frequency of individual occurrences with such a diplotype may lead to the increase in the mass index of the population as a whole.

\section{Discussion}

Genetic potential assessment of agricultural animal productivity by genetic markers is a modern, popular and rapidly developing trend in breeding. Currently, the search for effective genetic markers is carried out among the candidate genes for different traits in different breeds.

It is known that the growth process in mammals is significantly influenced by the growth hormone (GHsomatotropin) and a group of hormones involved in mediating its effect on target cells (somatotropin cascade). Among the genes responsible for the synthesis of the somatotropin cascade hormones, the search for potential candidate genes affecting the manifestation of quantitative traits in cattle, including beef productivity, is currently under way. We analyzed the effect of individual genotypes of $b G H, b G H R$ and $b I G F-1$ genes, as well as their paired combinations on the beef productivity of the Aberdeen-Angus breed.

It can be seen that groups of Aberdeen-Angus calves with the genotypes $b G H$-AluI ${ }^{\mathrm{LL}}, b G H-\mathrm{AluI}{ }^{\mathrm{LV}}$ and $b G H-\mathrm{AluI}{ }^{\mathrm{VV}}$ differ statistically significantly in live weight, index of bone at the age of 24 months and mass index at the age of 18 months. At the same time, groups of animals with the $b G H R$ $\mathrm{SspI}^{\mathrm{YY}}, b G H R-\mathrm{SspI}^{\mathrm{FF}}$ and $b G H R-\mathrm{SspI}^{\mathrm{FY}}$ genotypes for the $b G H R$-SspI polymorphism and groups of animals with the $b I G F-$ SnaBI ${ }^{\mathrm{AA}}, \quad b I G F-\mathrm{SnaBI} \mathrm{AB}^{\mathrm{AB}}$ and $\quad b I G F-\mathrm{SnaBI}^{\mathrm{BB}}$ genotypes for the $b G H R$-SspI polymorphism are homogeneous for all the considered traits (Table 2). Nonparametric characteristics of meat productivity of Aberdeen-Angus calves with different genotypes of $b G H$ AluI polymorphism are shown in Table 4.

Aberdeen-Angus calves with the $b G H-A l u I^{\mathrm{LV}}$ genotype have a lower mass index at the age of 18 months and a lower index of bone at the age of 24 months compared to their peers with the $b G H$-AluI ${ }^{\mathrm{LL}}$ and $b G H$ $\mathrm{AluI}{ }^{\mathrm{VV}}$ genotypes. In particular, the mass index at the age of 18 months in calves with the genotypes $b G H$-AluI ${ }^{\mathrm{LL}}$, $b G H-\mathrm{AluI}^{\mathrm{LV}}$ and $b G H-\mathrm{AluI}^{\mathrm{VV}}$ is $103.38(100.00 ; 105.51)$, 100.87 (99.15; 103.42) and 103.28 (100.85; 105.93) respectively. The bony index at 24 months in these groups of animals is 15.94 (15.26; 16.67), 15.50 (14.96; 16.28) and $15.50(15.00 ; 16.54)$ respectively (Table 4$)$. 
Laura Zhanedilovna Dushayeva et al. / OnLine Journal of Biological Sciences 2021, 21 (2): 334.345 DOI: 10.3844/ojbsci.2021.334.345

Table 4: Characteristics of the growth and development dynamics of Aberdeen-Angus calves with different genotypes of $b G H$-AluI polymorphism (Me [CI 95\%], (25\%; 75\%))

\begin{tabular}{|c|c|c|c|c|}
\hline Genotype & $b G H-\mathrm{AluI}^{\mathrm{LL}}$ & $b G H$-AluI ${ }^{\mathrm{LV}}$ & $b G H-\mathrm{AluI} \mathrm{I}^{\mathrm{VV}}$ & Total sample \\
\hline $\mathrm{n}$ & 83 & 126 & 74 & 284 \\
\hline Live weight/24 months & $\begin{array}{l}416 \\
{[410 ; 417],} \\
(408 ; 419)\end{array}$ & $\begin{array}{l}418 \\
{[414 ; 419],(411 ; 421)}\end{array}$ & $\begin{array}{l}417 \\
{[415 ; 422],} \\
(413 ; 425)\end{array}$ & $\begin{array}{l}417 \\
{[415 ; 418],} \\
(411 ; 422)\end{array}$ \\
\hline Index of bone/18 months & $\begin{array}{l}15.25 \\
{[15.13 ; 15.65],} \\
(14.59 ; 15.90)\end{array}$ & $\begin{array}{l}14.88[14.53 ; 15.25] \\
(14.41 ; 15.38)\end{array}$ & $\begin{array}{l}15.13 \\
{[14.53 ; 15.25],} \\
(14.41 ; 15.70)\end{array}$ & $\begin{array}{l}15.25[14.88 ; 15.25], \\
(14.41 ; 15.7)\end{array}$ \\
\hline Index of bone/24 months & $\begin{array}{l}15.94 \\
{[15.63 ; 16.30],} \\
(15.26 ; 16.67)\end{array}$ & $\begin{array}{l}15.50 \\
{[15.13 ; 15.70],} \\
(14.96 ; 16.28)\end{array}$ & $\begin{array}{l}15.50[15.13 ; 16.28], \\
(15.00 ; 16.54)\end{array}$ & $\begin{array}{l}15.63[15.45 ; 15.79], \\
(15.00 ; 16.53)\end{array}$ \\
\hline Mass Index/18 months & $\begin{array}{l}103.38 \\
{[101.68 ; 104.20],} \\
(100.00 ; 105.51)\end{array}$ & $\begin{array}{l}100.87 \\
{[100.00 ; 101.72],} \\
(99.15 ; 103.42)\end{array}$ & $\begin{array}{l}103.28 \\
{[101.68 ; 104.27],} \\
(100.85 ; 105.93)\end{array}$ & $\begin{array}{l}102.54 \\
{[101.67 ; 103.33]} \\
(100 ; 105.08)\end{array}$ \\
\hline
\end{tabular}

Aberdeen-Angus calves with the $b G H$-AluI ${ }^{\mathrm{VV}}$ genotype at the age of 24 months are characterized by increased live weight compared to their peers with the $b G H-\mathrm{AluI}^{\mathrm{LL}}$ and $b G H-\mathrm{AluI}^{\mathrm{LV}}$ genotypes. Calves live weight with genotypes $b G H$-AluI ${ }^{\mathrm{LL}}, b G H$-AluI ${ }^{\mathrm{LV}}$ and $b G H-\mathrm{AluI}^{\mathrm{VV}}$ at the age of 24 months is $416(408 ; 419), 41$ $(411 ; 421)$ and $417(415 ; 422) \mathrm{kg}$, respectively.

Our data correlate with the data of other researchers. For example, (Hartatik et al., 2020) found that the $b G H$ AluI ${ }^{\mathrm{V}}$ allele was positively associated with the average daily gain of cattle. In the work of (Plakhtyukova, 2020) it was shown that in the Kazakh white-headed breed group with $b G H$-AluI ${ }^{\mathrm{VV}}$ genotype, unlike the groups with other genotypes, large indicators of live weight, preslaughter and slaughter weight, as well as carcass weight, percentage of flesh in it, slaughter yield and meatability factor were observed.

However, a study by (Fedota et al., 2017b) in the Aberdeen-Angus breed found a positive correlation of $b G H$-AluI ${ }^{\mathrm{L}}$ allele with the increased animals' live weight at birth. In the work of (Sedykh et al., 2020) bulls of Hereford, Limousin and Black and White breeds with $b G H$ $\mathrm{AluI}^{\mathrm{LL}}$ genotype had significantly higher live weight, as well as absolute and average daily live weight gain. Akcay et al. (2015) showed no statistically significant differences in live weight between the groups of cattle with $b G H$-AluI ${ }^{\mathrm{LL}}, b G H$ AluI $^{\mathrm{LV}}$ and $b G H$-AluI ${ }^{\mathrm{VV}}$ genotypes.

Animal selection with preferred genotypes associated with meat productivity traits in cattle does not in all cases bring such a significant and rapid result as one would expect. Therefore, we conducted an additional evaluation of the genotypes phenotypic effect for polymorphisms that are potential genetic markers of Aberdeen-Angus breed productivity. It involves, after determining the preferred and undesirable genotypes for a given polymorphism, comparing the productivity indices of these groups of animals with the productivity indices of the total sample under study.

It is obvious that groups of Aberdeen-Angus calves with $b G H-\mathrm{AluI} \mathrm{I}^{\mathrm{LL}}$ and $b G H-\mathrm{AluI} \mathrm{I}^{\mathrm{VV}}$ genotypes are characterized by a significantly higher mass index relative to calves with $b G H$-AluI ${ }^{\mathrm{LV}}$ genotype (Fig. 4). At the same time, animals with the $b G H-$ AluI $^{\mathrm{LL}}$ and $b G H-\mathrm{AluI} \mathrm{IV}^{\mathrm{VV}}$ genotypes fall within the interquartile range of the total sample by the values of the mass index and the median confidence interval in the group with the $b G H$-AluI ${ }^{\mathrm{LV}}$ genotype was not done overlap with the median confidence interval of the sample. This indicates a significant difference between the group with the $b G H$ AluI ${ }^{\mathrm{LV}}$ genotype and the total sample. Thus, the genotype can be included in breeding programs as a genetic marker of reduced mass in Aberdeen-Angus calves at the age of 18 months. In this case, selection should be focused on reducing the number of calves with this genotype.

Genotypes that individually are not associated with meat productivity traits in paired combinations can exhibit increased or decreased, statistically significant phenotypic effect compared to the total sample, so in our work we evaluated the complex effect of $b G H, b G H R$ and $b I G F-1$ genes on meat productivity of Aberdeen-Angus cattle. We hypothesized that the phenotypic effect of genetic markers could be more pronounced if genetic markers potentiating each other's effect were present in the animal's genotype. Therefore, we took for the study such genes whose protein products are the key links of one humoral chain involved in the processes of growth and development of mammals ( $b G H, b G H R, b I G F-1)$ (Belaya et al., 2012b).

It is obvious that the boundaries of the median confidence interval of the group with the No $15 \mathrm{bGH}$ AluI ${ }^{\mathrm{VV}}-b I G F-1-\mathrm{SnaBI}^{\mathrm{BB}}$ diplotype are in the range from 420 to $431 \mathrm{~kg}$ and fall outside the median confidence interval of the sample of 415-418 kg for this trait (Fig. 5). When compared with the Aberdeen-Angus breed standard, it was found that the animal live weights with the $b G H-\mathrm{AluI}{ }^{\mathrm{VV}}-b I G F-1-\mathrm{SnaBI}^{\mathrm{BB}}$ diplotype at the age of 24 months exceeds the live weight of the Aberdeen-Angus breed standard by $45 \mathrm{~kg}(12 \%)$; and when compared with the General sample - by $12.52 \mathrm{~kg}(3 \%)$. This indicates that diplotype No.15 $b G H$-AluI ${ }^{\mathrm{VV}}-b I G F-1-\mathrm{SnaBI}^{\mathrm{BB}}$ can be recommended as a genetic marker of increased live weight of Aberdeen-Angus calves at the age 24 months. 
Diplotype No. $25 b G H R-\mathrm{SspI}^{\mathrm{FF}}-b I G F-1-\mathrm{SnaBI}^{\mathrm{BB}}$ is characterized by a significantly decreasing phenotypic effect on the Index of Compactness of Aberdeen-Angus calves at 24 months. The boundaries of the median confidence interval of the group with the diplotype are in the range from 81.82 to 84.24 and fall outside the confidence interval of the sample median, which are 84.08-85.63 for this indicator (Fig. 6). Average values comparison of the downness index in animals with the $b G H R-S$ spI $^{\mathrm{FF}}-b I G F-1-\mathrm{SnaBI}{ }^{\mathrm{BB}}$ diplotype and in the General sample showed that animals with this diplotype at the 24 months age are characterized by a lower value of the downness index, the difference from the General sample was $3.74 \%$. This suggests that diplotype No. 25 $b G H R$-SspI $I^{\mathrm{FF}}-b I G F-1-\mathrm{SnaBI}^{\mathrm{BB}}$ can be recommended as a genetic marker of the reduced Index of Compactness of Aberdeen-Angus calves at the 24 months age.

The group with diplotype No.1 $b G H$-AluI ${ }^{\mathrm{LL}}-b I G F-1$ $\mathrm{SnaBI}^{\mathrm{AA}}$ also falls outside the confidence interval of the sample median. However, in this case, the phenotypic effect is increasing for this indicator. In particular, in the calves' group with diplotype 1, the median of the sample is in the range from 86.45 to 85.44 , while for the total sample, this indicator is in the range of 84.08-85.63. The $b G H$-AluI ${ }^{\mathrm{LL}}-b I G F-1-\mathrm{SnaBI}^{\mathrm{AA}}$ diplotype score is $2.93 \%$ higher than the total sample. This makes it possible to recommend diplotype No.1 $b G H$-AluI ${ }^{\mathrm{LL}}-b I G F-1$ $\mathrm{SnaBI}^{\mathrm{AA}}$ as a genetic marker of increased churn in Aberdeen-Angus calves aged 24 months and diplotype No. $25 b G H R-\mathrm{SspI}^{\mathrm{FF}}-b I G F-1-\mathrm{SnaBI}^{\mathrm{BB}}$ as a marker of a reduced compactness index in such calves.

The confidence interval boundaries of the group median with diplotype No.11 $b G H$-AluI ${ }^{\mathrm{LV}}-b G H R-\mathrm{Sspl}^{\mathrm{FY}}$ are in the range from 99.15 to 101.54 and fall outside the median confidence interval of the sample 101.67-103.33 for this trait (Fig. 7). Compared to the General sample, the average value of the massiveness animal index with the $b G H-\mathrm{AluI}^{\mathrm{LV}}$ $b G H R$-SspI ${ }^{\mathrm{FY}}$ diplotype at 18 months is $3.98 \%$ lower. This suggests that diplotype No. $11 b G H-\mathrm{AluI}^{\mathrm{LV}}-b G H R-\mathrm{Sspl}^{\mathrm{FY}}$ can be recommended as a genetic marker of the reduced mass index of Aberdeen-Angus calves at the 18 months age.

Unfortunately, it is not possible to compare our results with those other researchers due to their limitations. Most scientific works are devoted to studies of the complex genotypes influence on milk productivity and milk quality in dairy breeds (Belaya et al., 2012b; Plivachuk and Dyman, 2016; Tyulkin, 2018; Safina et al., 2018; Mauriae et al., 2017; Lazebnaya et al., 2012).

The results we obtained for the Aberdeen-Angus breed differ from those obtained for the Auliekol and Kazakh white-headed breeds. Thus, in this study, the diplotype $b G H-\mathrm{AluI}^{\mathrm{LL}}-b I G F-1-\mathrm{SnaBI}^{\mathrm{AA}}$ is the marker of increased knockdown in Aberdeen-Angus animals and the diplotype $b G H-A l u I^{\mathrm{VV}}-b I G F-1-\mathrm{SnaBI}^{\mathrm{BB}}$ is the increased live weight markers of Aberdeen-Angus animals. Previously, we identified $b G H$-AluI ${ }^{\mathrm{LL}}-b I G F-1-\mathrm{SnaBI}^{\mathrm{AA}}, \quad b G H$-AluI ${ }^{\mathrm{LL}}-$ $b I G F-1-\mathrm{SnaBI}^{\mathrm{BB}}$ diplotypes that decrease live weight and $b G H-\mathrm{AluI}^{\mathrm{LV}}-b I G F-1-\mathrm{SnaBI}^{\mathrm{AB}}$ and $b G H$-AluI ${ }^{\mathrm{LV}}-b I G F-1-$
$\mathrm{SnaBI}^{\mathrm{BB}}$ diplotypes that increase live weight. The association of diplotypes with meat productivity of Auliekol and Kazakh white-headed cattle, whose structure includes the $b G H-\mathrm{AluI} \mathrm{I}^{\mathrm{VV}}$ genotype, was not identified, due to the fact that this genotype was rare (Nametov et al., 2019; Beishova et al., 2018). Thus, there are a number of limitations that prevent the direct translation of information obtained in one breed into breeding programs involving other breeds. This is due to the fact that, firstly, any gene works against the background of the whole set of genes of the organism and their polymorphic variants and the polymorphism preferred against one genome may turn out to be neutral or undesirable against the work of another genome. Secondly, the same breed in the local selection course in a certain territory adapts to the climate conditions, forage and diseases prevalent in this territory and acquires its own characteristics of physiology, phenotype and genotype. Consequently, the data on the association of a particular polymorphic candidate gene with productivity traits require additional studies on the population in which a breeding program using this DNA marker is conducted.

The effectiveness of including genotypes marking pairs in breeding programs depends to a certain extent on the starting frequency of the genotype in the population. The comparison results of the observed genotype frequencies for the $b G H$-AluI polymorphism were compared to the theoretically expected frequencies for the Hardy-Weinberg law.

At the age of 24 months in Aberdeen-Angus calves, diplotype No.15 $b G H$-AluI ${ }^{\mathrm{VV}}-b I G F-1-\mathrm{SnaBI}^{\mathrm{BB}}$ was a genetic marker of the increased live weight. Its frequency in the population was low and amounts to $8.15 \%$, while the frequencies of the structure-forming genotypes $b G H$ $\mathrm{AluI}^{\mathrm{VV}}$ and $b I G F-1-\mathrm{SnaBI}^{\mathrm{BB}}$ reach 26.5 and $23.26 \%$, respectively. Therefore, it was quite possible to increase the frequency of animal occurrence with a marking diplo type during breeding activities and thus increase the overall level of live weight of the livestock at the 24 months age.

A reduced index marker of Aberdeen-Angus calves' compactness at the 24 months age was diplo type No.25 $b G H R-\mathrm{SspI}^{\mathrm{FF}}-b I G F-1-\mathrm{SnaBI}^{\mathrm{BB}}$. Its frequency in the population is quite high at $17.93 \%$, while the frequencies of the structure-forming genotypes $b G H R-\mathrm{SspI}^{\mathrm{FF}}$ и $b I G F$ $1-\mathrm{SnaBI}^{\mathrm{BB}}$ are 73.4 and $23.26 \%$, respectively. In this case, breeding measures aimed at increasing the index of compactness of livestock should be focused on reducing the frequency of the combined diplo type No.25 $b G H R$ $\mathrm{SspI}^{\mathrm{FF}}-b I G F-1-\mathrm{SnaBI}^{\mathrm{BB}}$ in the population.

Diplo type No.1 $b G H$-AluI ${ }^{\mathrm{LL}}-b I G F-1-\mathrm{SnaBI}^{\mathrm{AA}}$ is a marker of the increased compactness in Aberdeen-Angus calves aged 24 months. Its frequency in the population is quite low and amounts to $5.97 \%$, while the frequencies of the structure-forming genotypes $b G H$-AluI ${ }^{\mathrm{LL}}$ and $b I G F$ $1-\mathrm{SnaBI}^{\mathrm{AA}}$ are 29.2 and $29.07 \%$, respectively, which indicates the prospects of breeding measures to increase its frequency in the population. To assess the economic 
efficiency of including these diplotypes, an assessment of additional economic parameters of breeding is required.

\section{Conclusion}

As a result of the study of phenotypic effects of individual genes, it was found that the genotype $b G H$ AluI $^{\mathrm{LV}}$ was statistically significantly associated with a reduced mass index at 18 months of age. However, it is difficult to reduce its frequency in the course of breeding programs because of the occurrence high frequency in the population: 126 out of 284 animals studied were carriers of this genotype. In this case the selection should be focused on calves' reduction with such genotype in the population.

The combined effects analysis of genotypes paired combinations in Aberdeen-Angus calves aged 18 and 24 months revealed diplotypes associated with both increasing and decreasing phenotypic effects on the meat productivity indicators.

The genetic marker of a reduced mass index at the age of 18 months is diplotype No.11 $b G H$-AluI ${ }^{\mathrm{LV}}-b G H R$ $\mathrm{SspI}^{\mathrm{FY}}$. The average value of the massiveness index in this group is $99.23 \pm 0.09$, which is $3.98 \%$ lower than the total sample. The number of animals with this diplotype in the studied population is 31 heads. The relative frequency of the diplotype in the population is quite high-10.86\% and a decrease in the frequency of occurrence of individuals with such a diplotype can lead to an increase in the mass index of the population as a whole.

The genetic marker of the compactness reduced index in Aberdeen-Angus calves at the 24 months age may be diplotype No.25 $b G H R-\mathrm{SspI}^{\mathrm{FF}}-b I G F-1-\mathrm{SnaBI}^{\mathrm{BB}}$. The value of the churn index for this group is $81.22 \pm 0.6$, while for the General sample this indicator is $84.38 \pm 0.21$ (the difference is $3.74 \%$ ). Its frequency in the population is quite high (51 heads out of 284 studied) and amounts to $17.93 \%$ and breeding measures aimed at increasing the index of compactness of livestock should be focused on reducing the frequency of the combined diplotype No. 25 $b G H R-\mathrm{SspI}^{\mathrm{FF}}-b I G F-1-\mathrm{SnaBI}^{\mathrm{BB}}$ in the population.

Diplotype No.1 $b G H$-AluI ${ }^{\mathrm{LL}}-b I G F-1-\mathrm{SnaBI}^{\mathrm{AA}}$ is a genetic marker of the increased compactness in AberdeenAngus calves at 24 months age. In particular, in this group, the average value of the churn index is $86.85 \pm 0.8$, while for the General sample, this indicator is $84.38 \pm 0.21$ (the difference is $2.93 \%$ ). Its frequency in the population is 17 heads $(5.97 \%)$, which indicates the prospects of breeding measures to increase its frequency in the population.

At the 24 months age, the genetic marker of increased live weight is diplotype No.15 $b G H$-AluI ${ }^{\mathrm{VV}}-b I G F-1$ SnaBIBB. The average live weight at 24 months in this group is higher in relation to the total sample by $12.52 \mathrm{~kg} \mathrm{(3 \% )}$ and is $429.2 \pm 2.6 \mathrm{~kg}$, while the total sample is $416.68 \pm 0.90 \mathrm{~kg}$. Moreover, the animal live weights with this diplotype at the age of 24 months exceeds the live weight of the AberdeenAngus breed standard by $45 \mathrm{~kg}(12 \%)$. Its frequency in the population is low and amounts to $8.15 \%$ (23 heads in the studied population). During breeding activities, increasing the frequency of this diplotype can increase the overall level of live weight at the age of 24 months.

\section{Acknowledgement}

The work was carried out within the framework of the project of grant financing of the Ministry of education and science of the Republic of Kazakhstan for 2018-2020 "Complex genetic marking of meat productivity in cattle of Hereford and Angus breeds of Kazakhstan selection for genes that regulate growth rates" (state registration No. 0118RK00396).

\section{Author's Contributions}

All authors equally contributed in this study.

\section{Ethics}

This article is original and contains unpublished material. The corresponding author confirms that all other authors have read and approved the manuscript and no ethical issues have been involved.

\section{References}

Akcay, A., Akyüz, B., \& Bayram, D. (2015). Determination of the AluI polymorphism effect of bovine growth hormone gene on carcass traits in Zavot cattle with analysis of covariance. Turkish Journal of Veterinary and Animal Sciences, 39(1), 16-22. http://doi.org/10.3906/vet-1404-29

Barendse, W., Bunch, R. J., Kijas, J. W., \& Thomas, M. B. (2007). The effect of genetic variation of the retinoic acid receptor-related orphan receptor $\mathrm{C}$ gene on fatness in cattle. Genetics, 175(2), 843-853. https://doi.org/10.1534/genetics.106.064535

Beishova, I. S., Belaya, E. V., Baimishev, H. B., \& Traisov, B. B. (2018). Effect of combinations of somatotropic genes on meat productivity of cattle. Proceedings of the Samara State Agricultural Academy, 2: 51-57. https://journals.ecovector.com/1997-3225/article/view/22661

Belaya, E. V., Mikhailova, M. E., \& Batin, N. V. (2012a). Assessing the individual phenotypic effect of polymorphic variants of the genes of hypophysial growth factor-1 [bPit-1] and insulin-like growth factor1 [bIGF-1] on milk productivity in motley Holsteinized cattle. Molecular and Applied Genetics, 13, 30-35.

Belaya, E. V., Mikhailova, M. E. \& Batin, N. V. (2012b). Combined phenotypic effects of polymorphic variants of somatotropin cascade genes (bPit-1, bPRL, bGH, bGHR and bIGF-1) on signs of milk productivity in Holstein cattle. Molecular and Applied Genetics, 13: 36-43. https://igc.by/wpcontent/uploads/2016/08/\%D0\%A2\%D0\%BE\%D0 $\%$ BC-13.pdf 
Fedota, O. M., Lysenko, N. G., Ruban, S. Y., Kolisnyk, O. I., \& Goraychuk, I. V. (2017a). The effects of polymorphisms in growth hormone and growth hormone receptor genes on production and reproduction traits in Aberdeen-Angus cattle (Bos taurus L., 1758). Cytology and Genetics, 51(5), 352-360. https://doi.org/10.3103/S0095452717050024

Fedota, O. M., Ruban, S. Y., Lysenko, N. G., Kolisnyk, A. I., Goraichuk, I. V., \& Tyzhnenko, T. V. (2017b). SNP L127V of growth hormone gene in breeding herd of Aberdeen Angus in Kharkiv region, Eastern Ukraine.

http://repo.knmu.edu.ua/bitstream/123456789/166 67/1/Fedota\%20O.M.\%20SNP\%20L127V.pdf

Fontanesi, L., Scotti, E., Tazzoli, M., Beretti, F., Dall'Olio, S., Davoli, R., \& Russo, V. (2007). Investigation of allele frequencies of the growth hormone receptor (GHR) F279Y mutation in dairy and dual purpose cattle breeds. Italian Journal of Animal Science, 6(4), 415-420. https://doi.org/10.4081/ijas.2007.415

Gui, L. S., Raza, S. H. A., Memon, S., Li, Z., Abd El-Aziz, A. H., Ullah, I., ... \& Liu, G. Y. (2020). Association of hormone-sensitive lipase (HSL) gene polymorphisms with the intramuscular fat content in two Chinese beef cattle breeds. Genomics, 112(6), 3883-3889. https://doi.org/10.1016/j.ygeno.2020.06.037

Hartatik, T., Fathoni, A. H. M. A. D., Bintara, S. I. G. I. T., Panjono, D. O. A. P., Widyobroto, B. P., Agus, A., ... \& Leroy, P. (2020). The genotype of growth hormone gene that affects the birth weight and average daily gain in crossbred beef cattle. Biodiversitas, 21(3), 941-945. https://doi.org/10.13057/biodiv/d210312

Hines, H., Ge, W., Zhao, Q., \& Davis, M. (1998). Association of genetic markers in growth hormone and insulin-like growth factor-I loci with lactation traits in Holsteins. Animal Genetics-Supplement, 29. https://insights.ovid.com/animal-genetics-

supplement/agens/1998/12/001/association-geneticmarkers-growth-hormone-insulin/233/00125507

Hohmann, L. G., Weimann, C., Scheper, C., Erhardt, G., \& König, S. (2020). Associations between maternal milk protein genotypes with preweaning calf growth traits in beef cattle. Journal of Animal Science, 98(10), skaa280. https://doi.org/10.1093/jas/skaa280

Lazebnaya, I. V., Lazebnyi, O. E., Maximenko, V. F., \& Sulimova, G. E. (2012). Polymorphism of growth hormone and prolactin genes in connection with milk quality determinants in cattle of the yaroslavskaya breed., (2), 39-44. https://doi.org/10.15389/agrobiology.2012.2.39eng

Liu, G. Y., Raza, S. H. A., Zhou, L., Abd El-Aziz, A. H., Sabek, A., Shoorei, H., ... \& Gui, L. S. (2020). The genetic polymorphisms of melanocortin-4 receptor gene are associated with carcass quality traits in a Chinese indigenous beef cattle breed. Research in Veterinary Science, 132, 202-206. https://doi.org/10.1016/j.rvsc.2020.06.011
Lysenko, N. G., Kolesnik, A. I., Goraichuk, I. V., Ruban, S. Yu., \& Fedota, A. M. (2016). Association of genes of the calpain-calpastatin system and parameters of animal exteriors of the Aberdeen-Angus breed. Factors of Experimental Evolution of Organisms, 18: 111-116. http://repo.knmu.edu.ua/handle/123456789/15034

MARK. (2008). Manual for the evaluation of cattle of beef breeds. Astana. The Ministry of agriculture of the Republic of Kazakhstan.

Mauriae, M., Mašek, T., Beniae, M., Špehar, M., \& Stareeviae, K. (2017). Effect of dgat1, FASN and PRL genes on milk production and milk composition traits in Simmental and crossbred Holstein cattle. Indian Journal of Animal Sciences, 87(7), 859-863. https://stoka.hpa.hr/UzgojneVrijednosti/Web/cattle/ pub/IJAS_2017_Mauric_et_al.pdf

Nametov, A. M., Beishova, I. S., Chuzhebaeva, G. D., Tegza, I. M., \& Belaya, A. V. (2018). Assessment Of Pairwise Combinations' Association Of Polymorphic Variants Of The Genes Of Bpit-1, Bgh, Bghr Bigf Somatotropic Cascade With Meat Productivity Of The Cattle Bred In Kazakhstan. Journal of Pharmaceutical Sciences and Research, 10(8), 1906-1911.

https://www.jpsr.pharmainfo.in/Documents/Volumes/v ol10Issue08/jpsr10081808.pdf

Nametov, A. M., Beishova, I. S., Kovalchuk, A. M., Poddudinskaya, T. V., \& Belaya, A. V. (2019). Analysis of the genetic structure of the hereford population bred in Kazakhstan. Advances in Animal and Veterinary Sciences, 7(Special Issue 1), 71-77. https://www.nexusacademicpublishers.com/uploads/ files/AAVS_7_s1_71-77.pdf

Plakhtyukova, V. R. (2020). Polymorphism of calpain and somatotropin genes in cattle of Kazakh white-headed breed and its relationship with productivity indicators. Dissertation for the degree of candidate of biological sciences: 06.02.07-Breeding, selection and genetics of farm animals, All-Russian Research Institute of sheep breeding and goat breeding - a branch of the Federal State Budgetary Scientific Institution "North Caucasian Federal Scientific Agrarian Center" and the Federal State Budgetary Educational Institution of Higher Education "Russian State Agrarian University Moscow Agricultural Academy named after K.A.Timiryazev", Stavropol, Russia, 142 p. http://www.stgau.ru/science/dis/avtoreferat/plakhtukov a_2020/01.pdf

Plivachuk, O. P., \& Dyman, T. M. (2016). Interdependence of complex genotypes of alfa-lactalbumin and betalactoglobulin with composition and technological properties of milk of ukrainian black-and-white dairy cattle. Animal Breeding and Genetics, 51, 124-131. https://doi.org/10.31073/ABG.51.17 
Posivnikova, M. V. (2017). Polymorphism of LGB, PRL, GH, PIT-1 and DGAT-1 genes and analysis of associations or genotypes with economic and useful characteristics of cattle. Dissertation for the degree of candidate of Biological Sciences: 06.02.07, All-Russian Scientific Research Institute of Genetics and Breeding of Agricultural Animals - a branch of the Federal State Budgetary Scientific Institution "Federal Scientific Center for Animal Husbandry-VIZh named after academician L.K.Ernst", p. Lesnye Polyany, Moscow region, 138 p. http://xn--blagiaphcs.xn-p1ai/rus/files/Zaschita/Pozovnikova/pozovnikovamv -dissertaciya.pdf

Purfield, D. C., Evans, R. D., \& Berry, D. P. (2019). Reaffirmation of known major genes and the identification of novel candidate genes associated with carcass-related metrics based on whole genome sequence within a large multi-breed cattle population. BMC Genomics, 20(1), 1-17. https://doi.org/10.1186/s12864-019-6071-9

Raza, S. H. A., Khan, R., Abdelnour, S. A., El-Hack, A., Mohamed, E., Khafaga, A. F., ... \& Zan, L. (2019). Advances of molecular markers and their application for body variables and carcass traits in Qinchuan cattle. Genes, 10(9), 717. https://doi.org/10.3390/genes 10090717

Rebrova, O. Y. (2002). Statistical analysis of medical data. Moskva: MediaSfera, 312. ISBN-10: 5-89084-013-4.

Safina, N. Y., Yulmetieva, Y. R., \& Shakirov, Sh. K. (2018). Effect of complex polymorphism of genes $\kappa$ casein (CSN3) and prolactin (PRL) on milk productivity of cows of Holstein breed. Dairy Farming Gazette, 1(29); 74-82. https://doi.org/10.24411/2225-4269-2018-00008

Sedykh, T. A., Dolmatova, I. Y., Valitov, F. R., Gizatullin, R. S., \& Kalashnikova, L. A. (2020). The Influence of Growth Hormone Gene Polymorphism on Growth Rate of Young Cattle. Iranian Journal of Applied Animal Science, 10(3), 445-451. http://ijas.iaurasht.ac.ir/article_675327.html

Siadkowska, E., Zwierzchowski, L., Oprzadek, J., Strzalkowska, N., Bagnicka, E., \& Krzyzewski, J. (2006). Effect of polymorphism in IGF-1 gene on production traits in Polish Holstein-Friesian cattle. Animal Science Paper Rep, 24(3), 225-237. https://www.igbzpan.pl/uploaded/FSiBundleContent BlockBundleEntityTranslatableBlockTranslatableFil esElement/filePath/270/strona225-238.pdf
Skinkytè, R., Zwierzchowski, L., Riaubaitè, L., Baltrènaitė, L., \& Miceikienė, I. (2005). Distribution of allele frequencies important to milk production traits in lithuanian black \& white and lithuanian red cattle. Veterinarija ir Zootechnika, 31(53). https://vetzoo.lsmuni.lt/data/vols/2005/31/pdf/skink yte.pdf

Szewczuk, M. (2016). Effects of SNP within exon 7 of the insulin-like growth factor receptor type 1 (IGF1R) gene on growth traits in Angus cows. https://doi.org/10.1501/tarimbil_0000001407

Tyulkin, S. V. (2018). The effect of cows genotype on their productivity and Milk quality. Food Systems, 1(3), 38-43. https://doi.org/10.21323/2618-97712018-1-3-38-43

Wang, D., Liu, L., Augustino, S. M., Duan, T., Hall, T. J., MacHugh, D. E., ... \& Yu, Y. (2020). Identification of novel molecular markers of mastitis caused by Staphylococcus aureus using gene expression profiling in two consecutive generations of Chinese Holstein dairy cattle. Journal of Animal Science and Biotechnology, 11(1), 1-17. https://doi.org/10.1186/s40104-020-00494-7

Wu, S., Ning, Y., Raza, S. H. A., Zhang, C., Zhang, L., Cheng, G., ... \& Zan, L. (2019). Genetic variants and haplotype combination in the bovine CRTC3 affected conformation traits in two Chinese native cattle breeds (Bos Taurus). Genomics, 111(6), 1736-1744. https://doi.org/10.1016/j.ygeno.2018.11.028

Xiang, R., Berg, I. V. D., MacLeod, I. M., Hayes, B. J., Prowse-Wilkins, C. P., Wang, M., Bolormaa, S., Liu, Zh., Rochford, S. J., Reich, C. M., Mason, B. A., Jagt, Ch. J. V., Daetwyler, H. D., Lund, M. S., Chamberlain, A. J., \& Goddard, M. E. (2019). Quantifying the contribution of sequence variants with regulatory and evolutionary significance to 34 bovine complex traits. Proceedings of the National Academy of Sciences, 116(39); 19398-19408. http://dx.doi.org/10.1073/pnas.1904159116

Zhang, F., Wang, Y., Mukiibi, R., Chen, L., Vinsky, M., Plastow, G., ... \& Li, C. (2020). Genetic architecture of quantitative traits in beef cattle revealed by genome wide association studies of imputed whole genome sequence variants: I: Feed efficiency and component traits. BMC Genomics, 21(1), 1-22. https://doi.org/10.1186/s12864-019-6362-1 